\title{
UV-Vis Study of Mixed Collector Adsorption on Pyrite towards the Better Understanding of the Adsorption Mechanism
}

\author{
Akira Otsuki $^{1 *}$, Yihong Zhao ${ }^{2}$ \\ ${ }^{1}$ Ecole Nationale Supérieure de Géologie, GeoRessources UMR 7359 CNRS, University of Lorraine, 2 Rue du Doyen \\ Marcel Roubault, BP 10162, 54505, Vandoeuvre-lès-Nancy, France. \\ ${ }^{2}$ WA School of Mines, Curtin University, Kalgoorlie, Australia \\ Email: akira.otsuki@univ-lorraine.fr
}

\begin{abstract}
This paper discusses the primary collector adsorption onto a sulphide mineral in mixed collector systems to further understand its adsorption mechanism. UV-Vis measurements were performed to identify the primary collector concentration adsorbed on pyrite, and the adsorption kinetics under different conditions were compared to distinguish their difference between single and mixed collector systems. Small amount of secondary collector addition prior to the primary collector addition significantly improved the adsorption kinetics of primary one. The result was explained by the combination of two previously proposed mechanisms (i.e., different adsorption site mechanism and multi-layer product mechanism). This study showed UV-Vis measurement as an effective tool to study mixed collector adsorption behavior.
\end{abstract}

Keywords: Primary collector; secondary collector; adsorption kinetics; sulphide.

\section{$1 \quad$ Introduction}

Collectors are surfactants composed of heteropolar molecules with a non-polar and a polar group [1]. In a froth flotation process, the function of collector is to improve the hydrophobicity of target minerals and selectively float them with the aid of gas bubbles. Because of the chemical or physical attraction between the polar group and the mineral surfaces sites, collector molecules adsorb on the particle surface with the non-polar group assigned towards the bulk solution (i.e., water), thus the mineral particle surface becomes hydrophobic [2].

Thiol collectors are major collectors widely used in sulphide mineral flotation. Potassium amyl xanthate (PAX), dithiocarbamate (DTC), dithiophosphate (DTP), mecaptobenzothiazole (MBT) are some common thiol collectors. Previous studies reported that some mixed collector systems enhanced the flotation performance [e.g., 3-5]. Thiol collector mixtures are often used in the flotation of sulphide ores, and discussed with the synergistic benefits [6] which include reducing the total collector dosage requirements, improving the sulphide recovery and the rate of flotation as well as the improving the froth characteristics. The current paper mainly considered the mixture between two thiol collectors (PAX and DTC, considered as a weaker and selective collector, and stronger and less selective collector, respectively [3]) to further understand their adsorption mechanism that should assist in improving the flotation performance of refractory gold ores that often host gold in pyrite grains.

From previous studies [e.g. 1,4,7-9], it is well known that there are synergistic effects in flotation when using mixed collectors. The word "synergism" means that the effect of the collector combinations on the flotation performance is better than the effect of simple summation of single collector performances [4]. A study reported when using a mixed collector system of a weak collector and a strong collector, the flotation recovery increased $2-5 \%$ compared with that of the single strong collector system [10]. Glembotskii [10] also stated that the larger the difference between the structures and compositions in two collectors, the stronger the synergistic effect. This effect is more noticeable at lower collector dosage [1]. Experimental evidence indicated an improved flotation performance with mixed collectors, but there is no clear understanding about the synergistic mechanism. Some mechanisms were proposed in previous studies. Plaskin and Zaitseva (1960) [7] concluded that different sorption sites had different activities to the different collectors, and thus led the higher adsorption kinetics and thus a greater rate of flotation. 
They also suggested that mixed collectors form a more evenly distributed surface film because of a better orientation of different collectors.

Woods (1994) [11] stated that a mixture of chemisorption type and physisorption type collectors can achieve a better distribution with more strongly adhered chemisorption species and less hydrophobic physisorbed dithiolates. These could result in a multilayer surface product and increase the mineral surface hydrophobicity and a stronger attachment between bubble and particle [11]. In the single collector flotation system, its performance depends on many factors such as $\mathrm{pH}$ value $[12,13]$, reagent type and dosage [12], adding sequence of the reagents [8]. In a mixed collector system, the enhanced effect on flotation performance is also influenced by these factors. In relation to the adding sequence, Woods (1994) [11] proposed bilayer product formation in the mixed collector system. The first adsorbed layer is a chemisorption type collector and it provides the sites for the following physisorption type collector. Therefore, if this mechanism is correct, the multi-layer product will not form if the physisorption type collector is added first. The experiment results from Bradshaw (1997) [3] indirectly supported this mechanism. In her study, when the physisorption type xanthate was added first, the sulphide grade was lower than when the chemisorbed DTC was added first.

Bagci et al. (2007) [9] illustrated the above two mechanisms with incorporating the concepts of selective (e.g. di-isobutyl dithiophosphinate, DTPI) and less selective (e.g. isopropyl xanthate, SIPX) collector, based on the electronegativity of atoms $(\mathrm{O}>\mathrm{N}>\mathrm{S}>\mathrm{P})$ composing a collector. The following Figs. 1 and 2 explain the two mechanisms, with further incorporating the collector strength $($ DTC $>$ xanthate) and selectivity (xanthate $>$ DTC) [3], in order to directly link with the present study.

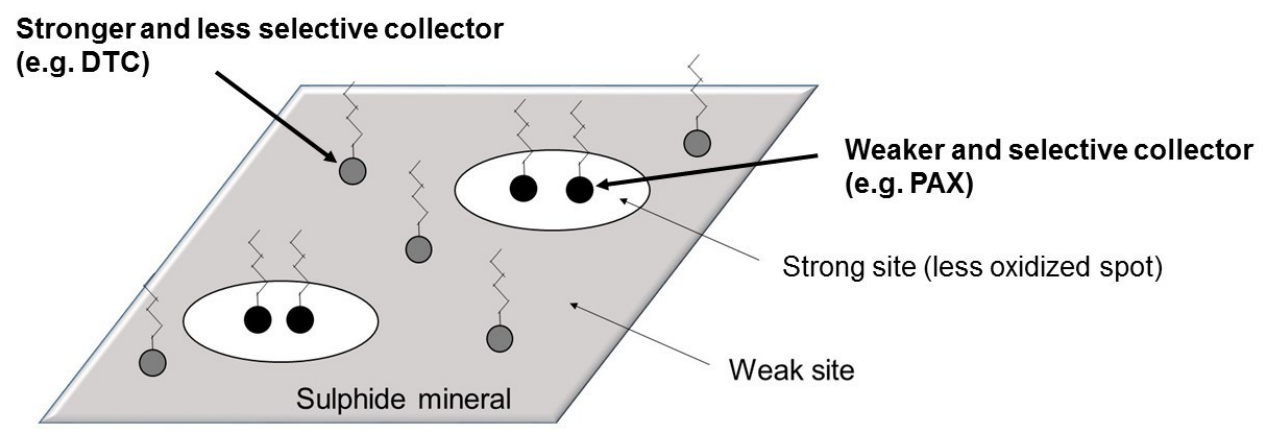

Figure 1. Schematic illustration of different adsorption site mechanism (modified from [9]).

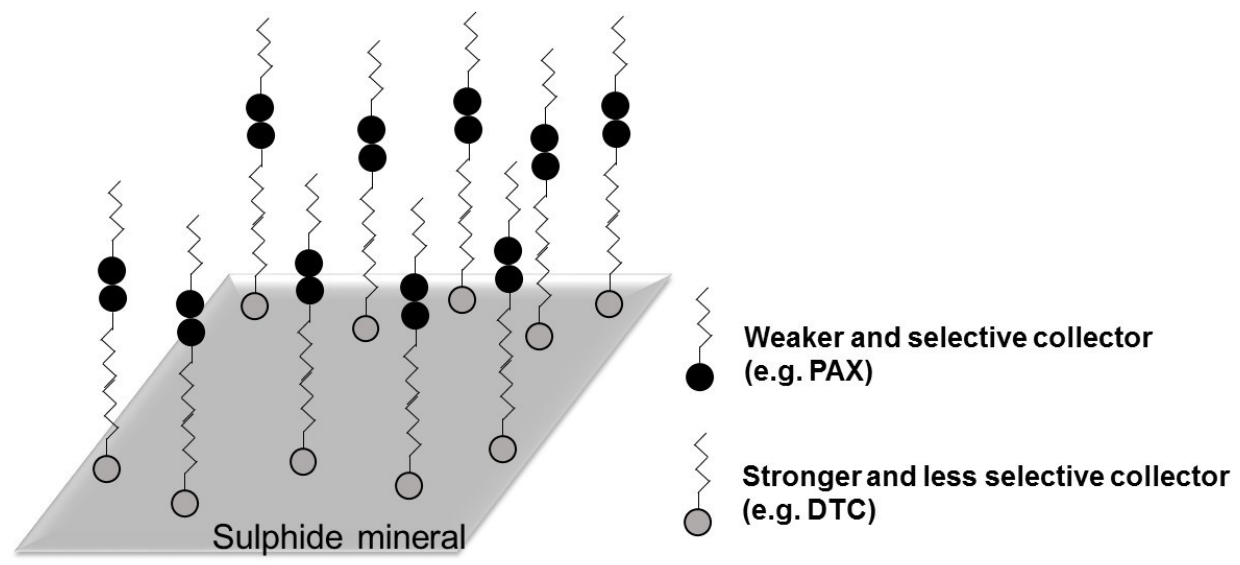

Figure 2. Schematic illustration of multi-layer adsorption mechanism (modified from [9]).

The previously reported method to investigate adding sequence was reasonable; however, the test and logic to obtain the best dosage and ratio only consider the pure compensation effect of the mixed collector system, without considering the synergism. This is a typical example on how a mixed collector system is designed without the fundamental understanding of the mixed collector adsorption mechanisms. Within this context, one of the most important issues to be addressed is how to 
systematically analyze this synergism in order to select a proper collector combination for ore beneficiation by flotation.

Ultraviolet-Visible (UV-Vis) spectroscopy is a potential solution provider who can indirectly analyse the reaction kinetics. It can provide the absorption spectra in the UV-Vis region by the sample solution and thus able to identify the product types from various reactions and semi-quantify its concentration. In a mineral-collector system (e.g., pyrite-xanthate), the collector in the mineral suspension can be adsorbed onto the mineral surfaces. The UV-Vis measurement monitors the absorption spectra at a certain wavelength to determine the adsorption of collector on the mineral surface [3]. Then the change of collector concentration can be calculated using the Lambert-Beer equation from the change in the magnitude of absorbance. Spectrophotometric method could also provide complementary information on the nature of the adsorbed species. Usually these measurements together with electrochemical method [e.g., 14] confirm the identity of the products of various reactions in flotation.

This study investigated the mechanism of thiol collector adsorption on sulphide mineral (pyrite) surface with a combination of thiol collectors (i.e., dithiocarbamate and xanthate). The benefits of using a mixed collector system depend on not only the thiol collector combination but also the collector adding sequence. This study can contribute to better understanding the mixed thiol collector adsorption mechanism on sulphide minerals and the implementation of mixed collector systems in flotation of refractory gold ores whose major host mineral is often sulphide (e.g. pyrite).

\section{$2 \quad$ Materials and Methods}

\section{$2.1 \quad$ Materials}

Pure pyrite $\left(\mathrm{FeS}_{2}\right)$ was obtained from BK Minerals. Potassium amyl xanthate $\left(\mathrm{PAX} ; \mathrm{C}_{6} \mathrm{H}_{11} \mathrm{KOS}_{2}\right)$ was purified using acetone, and dialkyl dithiocarbamate (DTC) was AERO 3740 from Cytec. PAX and AERO 3740 solutions were prepared at concentrations of 0.001 and $0.0001 \% \mathrm{w} / \mathrm{v}$, respectively. Those concentrations were experimentally predetermined from the UV-Vis spectra to maximize the clarity of the peaks from the primary collector PAX.

\subsection{Methods}

Figure 3 shows the flowsheet explaining the sample preparation and UV-Vis measurement procedure. Just prior to the UV-Vis measurement, pyrite was dry ground with a ceramic mortar and pestle in order to avoid oxidation of pyrite, and was sieved using a $75 \mu \mathrm{m}$ opening screen. The above mentioned grinding and sieving were performed in a glove box with nitrogen purging to avoid the oxidation of pyrite. A $1.4 \mathrm{~g}$ of $-75 \mu \mathrm{m}$ pyrite was transferred to a conical flask with $200 \mathrm{~mL}$ distilled water, and conditioned for $30 \mathrm{~min}$. During the conditioning time, the mineral suspension was stirred using a magnetic stirrer. To avoid oxidation of pyrite, the conical beaker was sealed by a stopper and nitrogen was injected into the beaker constantly (Fig. 4) from the beginning to the end of the conditioning (i.e., $30 \mathrm{~min}$ without the collector(s) and then $100 \mathrm{~min}$ with the collector(s)). The pyrite suspension conditioned for a designed period with collectors was analysed by the UV-Vis spectrophotometer, LAMBDA 35 (Perkin Elmer), with scanning wavelength from 200 to $500 \mathrm{~nm}$. Obtained absorption spectra was compared and used to analyse the total collector adsorption onto pyrite particles as a function of time to identify the adsorption kinetics under different conditions. The spectra were obtained at sampling time $0,0.5,5,50$, and $100 \mathrm{~min}$, following the $30 \mathrm{~min}$ initial conditioning without collector. The initial sampling time (i.e., $0 \mathrm{~min}$ ) started counting at the time of the primary collector (PAX) addition. Prior to the transportation of the solution to the UV-Vis cell, a $45 \mu \mathrm{m}$ filter was used to obtain a clear solution for the measurement by removing pyrite particles that may hide the spectra from the collectors. Filtration eliminated pyrite particles and thus the peaks at $300 \mathrm{~nm}$ from xanthate were observed clearly (Fig. 5). 


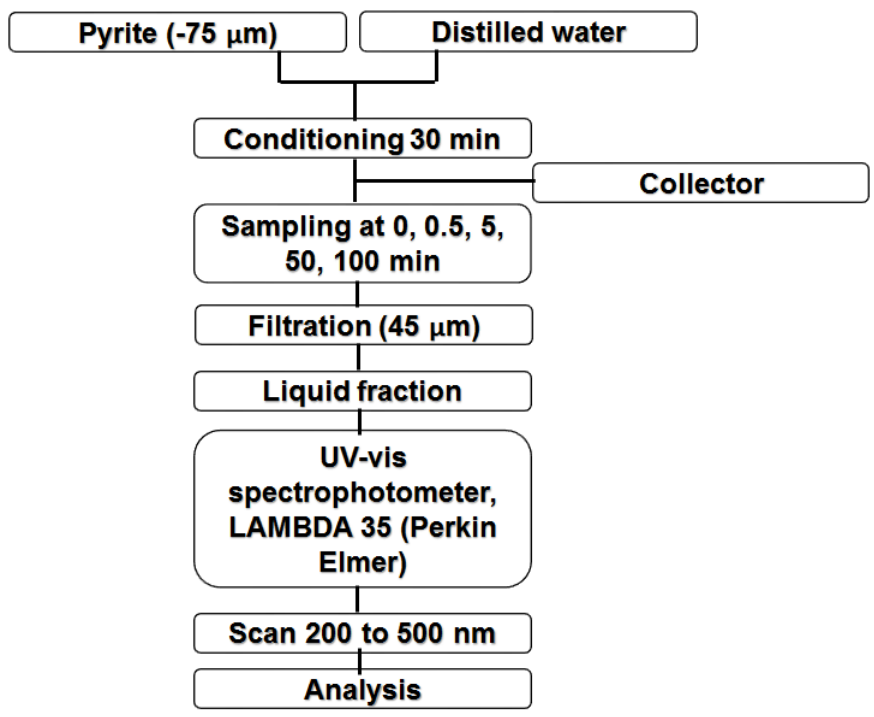

Figure 3. Flowsheet of sample preparation and UV-Vis measurement.

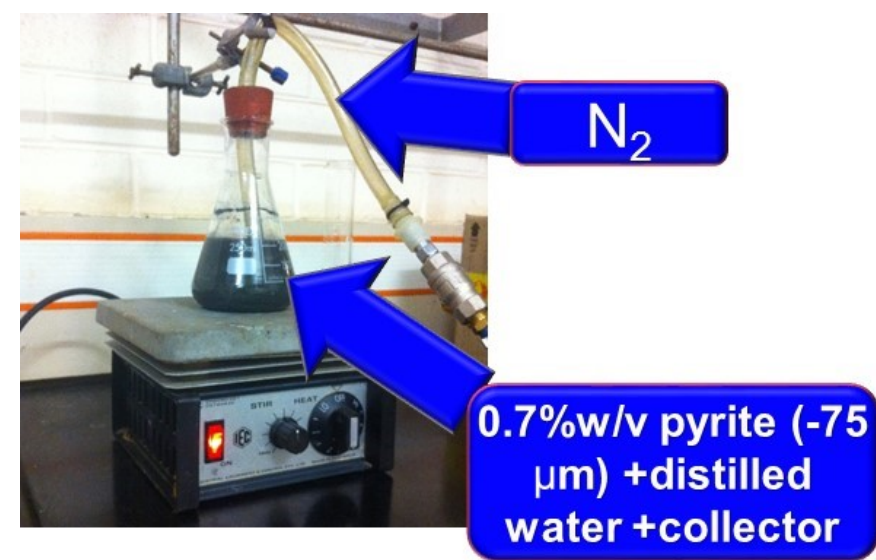

Figure 4. Experimental setup for sample preparation.

For the single collector system, the adsorption spectra of $0.001 \% \mathrm{w} / \mathrm{v}$ PAX solution after conditioning with pyrite suspension were measured. For the mixed collector systems, collectors were added into the solution to make up $0.0001 \% \mathrm{w} / \mathrm{v}$ DTC (AERO 3740) with $0.001 \% \mathrm{w} / \mathrm{v}$ PAX, in order to compare their adsorption kinetics and then investigate the effect of secondary collector DTC on PAX adsorption.

\section{$3 \quad$ Results and Discussion}

To investigate the influence of a secondary collector (DTC) on the primary collector (PAX) adsorption on pyrite surface, the collector adsorption was indirectly measured by monitoring the change in the absorbance intensity of the PAX solution using the UV-Vis spectrometer. The absorbance value is directly related to the PAX concentration in solution. In other words, a higher PAX concentration remained in the solution means its low adsorption onto pyrite particles. Figure 5 shows one example of the absorbance with (a) single PAX collector system and (b) DTC-PAX mixture system, at the beginning $(0 \mathrm{~min})$ and the end $(100 \mathrm{~min})$ of the experiment. A peak at $300 \mathrm{~nm}$ was observed and compared under all the conditions. It agreed with the previously reported value for single xanthate adsorption on pyrite [15]. 


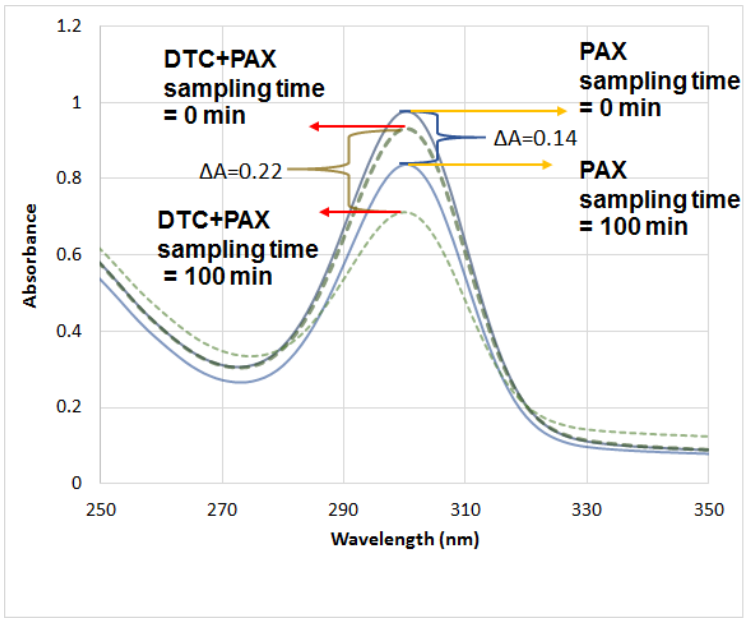

Figure 5. UV-Vis spectra at the sampling time 0 and $100 \mathrm{~min}$ using (a) $0.001 \% \mathrm{w} / \mathrm{v}$ potassium amyl xanthate and (b) $0.0001 \% \mathrm{w} / \mathrm{v}$ dithiocarbamate with $0.001 \% \mathrm{w} / \mathrm{v}$ potassium amyl xanthate.

Figure 5 shows that after 100 min conditioning there was a 0.14 decrease in the absorbance intensity for (a) PAX single collector system while a 0.22 decrease for (b) DTC-PAX mixture system, compared with the beginning (sampling time $0 \mathrm{~min}$ ). This decrease incorporates with the decrease of PAX concentration in the solution. In other words, the PAX adsorbed onto pyrite particles. The results indicate that when the mixed collector of DTC and PAX were used, there was a larger change in absorption, and thus the adsorbed amount of PAX onto pyrite surface increased. This comparison shows that the presence of the secondary collector DTC resulted in an increased amount of PAX adsorbed.

The extra xanthate adsorption in this experiment can be explained using the two mechanisms proposed by Woods (1994) [11] and Bagci et al. (2007) [9]. They suggested that the pyrite surface have different sorption sites for dithiocarbamate and xanthate. In this study, the formation of multilayer products on the surface was also indicated. When dithiocarbamate was added first, it occupied some of the adsorption sites (i.e. weak sites) where xanthate did not adsorbed onto. When the xanthate was added afterwards, it was not only adsorbed onto the adsorption site of pyrite surface, but was also adsorbed onto the extra sites provided by dithiocarbamate which resulted in an increasing amount of adsorbed potassium xanthate. The possible thiol collector adsorption models on pyrite in (a) PAX single and (b) DTC-PAX mixture system are shown in Figure 6. The idea will be further explained in the following paragraphs with the results of PAX adsorption kinetics.

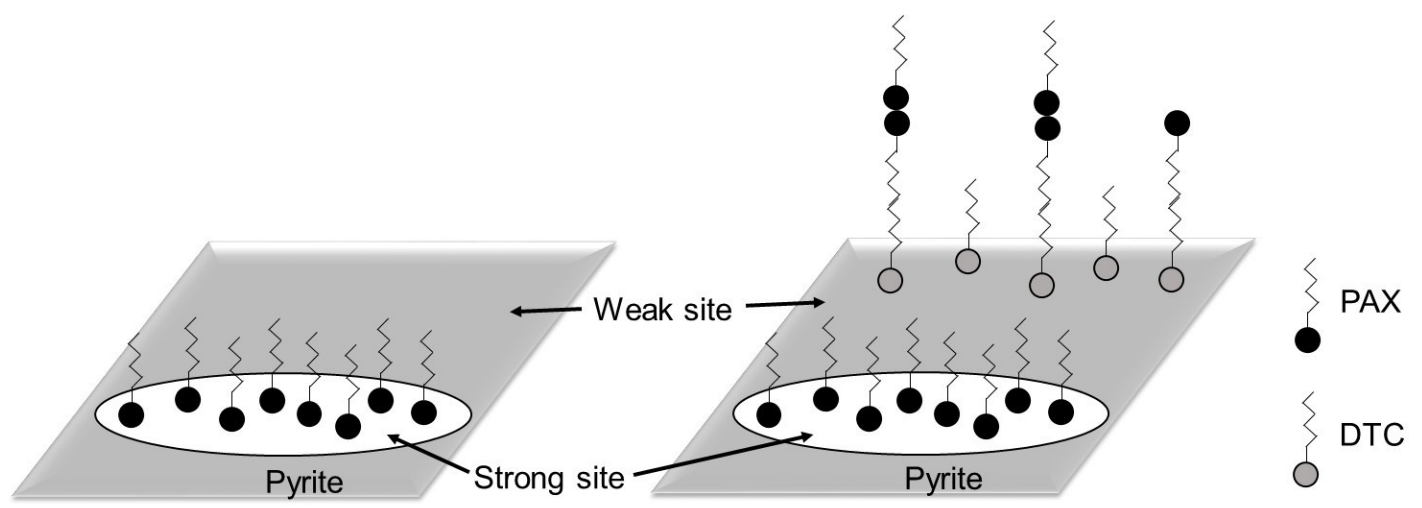

(a) PAX single system

(b) DTC-PAX mixture system

Figure 6. Model of collector adsorption onto a pyrite surface in the (a) PAX single system and (b) DTC- PAX mixture system. 
Figure 7 shows the adsorption rate change of PAX onto pyrite particles with (a) single PAX system and (b) DTC-PAX mixture system, calculated using the results obtained from the series of collector adsorption experiments with UV-Vis (e.g., results shown in Figure 5). The xanthate concentration changes were calculated using the Lambert-Beer Law shown in Eq. 1 by following the suggestion of Bradshaw 1997 [3].

$$
A=\varepsilon c l
$$

where $A$ is the absorbance of clear solution at a defined wavelength (300 $\mathrm{nm}$ in this study); $\varepsilon$ is the molar extinction coefficient $\left(\mathrm{L} \mathrm{mol}^{-1} \mathrm{~cm}^{-1}\right), c$ is the molar concentration $\left(\mathrm{mol} \mathrm{L}^{-1}\right)$ and $l$ is the path length of radiation $(\mathrm{cm})$. In this calculation, $A$ was the absorbance (no unit) from the UV-Vis spectra, molar extinction coefficient was $1.77 \times 10^{4}[16]$, and the cuvette path length was $1 \mathrm{~cm}$. The adsorption test monitored the reduction of the absorption peak indicating the decrease of xanthate concentration in the solution, and thus it was able to determine the concentration and thus rate of xanthate adsorption.

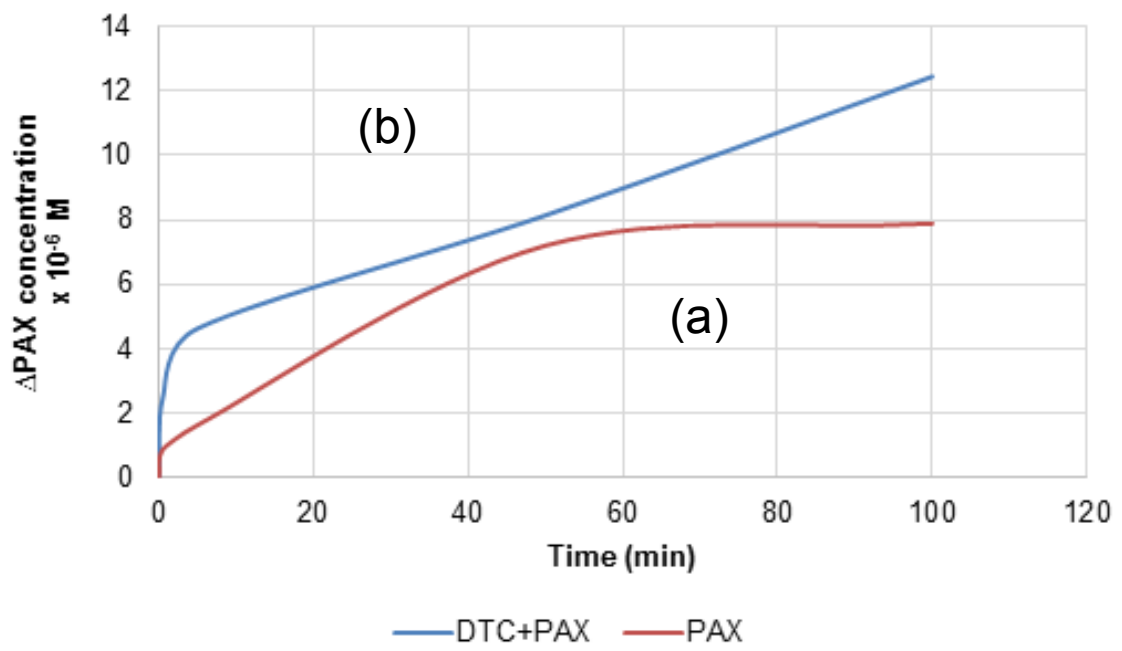

Figure 7. Adsorption rate of potassium amyl xanthate onto pyrite with (a) single PAX system and (b) DTC-PAX mixture system.

The DTC-PAX mixture system (Fig. 7-b) showed that in the first $5 \mathrm{~min}, 5 \times 10^{-6} \mathrm{M}$ of PAX was quickly adsorbed onto the pyrite surface and $8 \times 10^{-6} \mathrm{M}$ more PAX was accumulatively adsorbed onto the pyrite surface from 5 to $100 \mathrm{~min}$. On the other hand, the single PAX system (Fig. 7-a) showed that approximately $8 \times 10^{-6} \mathrm{M}$ was gradually adsorbed onto pyrite surface from 0 to 70 min slowly. After 70 min, there was no more PAX adsorption. Using the Lambert-Beer Law (Eq. 1), the initial concentration of the PAX in solution was determined as $5.4 \times 10^{-5} \mathrm{M}$. A $23 \%$ of the total PAX was adsorbed onto pyrite with DTC while only $15 \%$ PAX was adsorbed without DTC. This indicated that the primary collector PAX adsorption onto pyrite was improved by the secondary collector DTC addition, in terms of kinetics and the adsorption amount.

It can be seen that the adsorption rate in the first 5 min changed significantly. This phenomenon was inconsistent with Bradshaw's study (1997) [3]. In her study, the presence of dithiocarbamate does not increase the adsorption rate of xanthate and therefore no synergism effect was reported. In Figure 7, the adsorption rate between the single collector system and the mixed collector system were quite different while in Bradshaw's study, the curves were similar.

Figure 6 illustrates the above mentioned model. The different kinetics between single and mixture systems can be explained by the addition of the secondary collector DTC followed by the primary collector PAX. In DTC-PAX mixture system (Fig. 6-b), the low concentration DTC was added first prior to the PAX addition. Therefore, at the first few minutes, many of the DTC was adsorbed onto the bare pyrite surface and provided limited second layer site for PAX adsorption due to the hydrophobic interaction with hydrocarbon chains of DTC. A portion of PAX $\left(5 \times 10^{-6} \mathrm{M}\right)$ was adsorbed onto the second layer site and rest of xanthate $\left(8 \times 10^{-6} \mathrm{M}\right)$ was then adsorbed on the remained adsorption site on the bare pyrite surface which proceeded a slow adsorption. Considering the fact that the improvement in the pyrite flotation performance with this mixture system was achieved but not such 
significant compared with the single system (results not shown due to the confidentiality), some degree of pyrite hydrophobicity improvement was indirectly pronounced with the double layer formation of PAX explainable by van der Waals interaction [17] thus pointing its hydrophobic tails towards water on top of DTC as similar case suggested for SIPX [9] although the co-existence of PAX single layer. However, it is also possible that the addition of DTC can lead more PAX adsorption than the amount of DTC added. It was proved by the fact that the adsorption rate for the mixed collector system did not reach a plateau (Figure 7b). On the other hand, in the single collector system, the total PAX adsorption was approximately $8 \times 10^{-6} \mathrm{M}$ which can be explained by the sites available for PAX (i.e. strong site) on the bare pyrite surface being able to accept the adsorption of only a limited amount of xanthate.

\section{Conclusions}

Thiol collectors are often used in a mixed collector system for refractory gold ore flotation. Mixture of these collectors can result in better flotation performances. Previous studies investigated mixed thiol collector systems showing the benefits of the synergistic effects on sulphide mineral flotation performance in different systems. Synergistic effects have been observed in many aspects (i.e., valuable mineral recovery and grade, as well as kinetics). These effects of the mixed thiol collector have also been attributed to the faster adsorption, the improvement of recovery in coarse particles, increase in collector surface coverage, and improvement of froth characteristics. Although intensive studies have been carried out with different experimental approached (e.g., batch flotation tests, contact angle test, spectrophotometric test, thermal chemical test), the adsorption mechanism of mixed thiol collector on sulphide mineral surface has still not been clearly identified due to the complexity of the mixed collector floatation system. Therefore, the candidate selection for the mixed collector formulation is currently based on practical experience and trial. Thus, the adsorption mechanism of mixed thiol collector is important and worth to investigate because it can assist in designing the mixed collector system formulation for maximizing the flotation performance.

Previous studies proposed two major mechanisms of mixed thiol collector adsorption on pyrite surface. The first proposed mechanism is that the pyrite surface has different adsorption sites to accept different collectors, thus a mixture of different collectors can improve the total collector coverage on pyrite surface. Second proposed mechanism is a multi-layer product formation. Extra sites can thus be provided on top of the first layer of attached collectors to accept more collector adsorption, resulting in a combination of advantages from different collectors.

This study on the adsorption mechanism of thiol mixed collector on sulphide mineral revealed that: the addition of DTC prior to PAX significantly increased the PAX adsorption rate at the first five minutes and also increased the total amount of PAX adsorbed onto pyrite surface. It was explained by DTC and PAX adsorption onto different sites on pyrite surface and the DTC adsorption on the bare pyrite surface provided extra site for PAX to be adsorbed on. In this study, our proposed mechanism was a combination of the proposed different adsorptions site mechanism and multi-layer product mechanism.

\section{References}

1. Lotter, N.O., \& Bradshaw, D. J. (2010). The formulation and use of mixed collectors in sulphide flotation. Minerals Engineering, 23, 945-951.

2. Wills, B.A., \& Napier-Munn, T. (2006). Wills' mineral processing technology an introduction to the practical aspects of ore treatment and mineral recovery. 7th ed. Amsterdam; Boston; London: Elsevier/BH.

3. Bradshaw, D.J. (1997). Synergistic effect between thiol collectors used in the flotation of pyrite. PhD thesis, University of Cape Town.

4. Bradshaw, D.J., Harris, P.J., \& O'Connor, C.T. (1998). Synergistic interactions between reagents in sulphide flotation. J. South African Inst. Mining Metallurgy, 189-194.

5. Rao, K., Forssberg, K.S.E. (1997). Mixed collector systems in flotation. Int. J. Miner. Process. 51, 67-79. 
6. Bradshaw, D.J., Cruywagen, J.J., \& O'Connor, C.T. (1995). Thermochemical measurements of the surface reactions of sodium cyclohexyl-dithiocarbamate, potassium n-butyl xanthate and a thiol mixture with pyrite. Minerals Engineering, 8, 1175-1184.

7. Plaskin, I. N., \& Zaitseva, S. P. (1960). Effect of the combined action of certain collectors on their distribution between galena particles in a flotation pulp, (Mintek Translation No.1295, 1988) Naachnye Soobshcheniya Institut Gonnogo dela Imeni AA Skochinskogo, Akademiya Nauk SSSR, Moskva 6, 15-20.

8. Bradshaw, D.J., \& O'Connor, C.T. (1994). The flotation of pyrite using mixtures of dithiocarbamates and other thiol collectors. Minerals Engineering 7, 681-690.

9. Bagci, E., Ekmekci, Z., \& Bradshaw, D. (2007). Adsorption behaviour of xanthate and dithiophosphinate from their mixtures on chalcopyrite. Minerals Engineering, 20, 1047-1053.

10. Glembotskii, A.A. (1958). The combined action of collectors during flotation. Tsvetnye Metally, 4, 6-14.

11. Woods, R. (1994). Chemisorption of thiols and its role in flotation. A. Sutolov memorial volume. In: Castro, I. S. \& Alvares, J. (Eds.) V Meeting of Southern Hemisphere on Mineral Technology;and III Latin American Congress on froth flotation. Universidad de Conception, Conception, Chile.

12. O'Connor, C.T., \& Dunnew, R.C. (1991). The practice of pyrite flotation in South Africa and Australia. Minerals Engineering 4, 1057-1069.

13. Nguyen, A.V. (2007). Flotation. In: Poole, C.F., Cooke, M., Wilson, I.D. (Eds.). Encyclopedia of Separation Science, pp.1-27, Academic Press, London.

14. Wang, X.H., \& Forssberg, K.S.E. (1991). Mechanisms of pyrite flotation with xanthates. Int. J. Miner. Proc. 33, 275-290.

15. Montalti, M., Fornasiero, \& D., Ralston, J. (1991). Ultraviolet-visible spectroscopic study of the kinetics of adsorption of ethyl xanthate on pyrite. J. Colloid Interface Sci., 143, 440-450.

16. Fuerstenau, M.C. (eds.) (1976). Flotation: A.M. Gaudin memorial volume, Vol.1, American Institute of Mining, Metallurgical, and Petroleum Engineers, New York.

17. Nir, S. (1976). van der Waals interactions between surfaces of biological interest. Progress in surface science, 8, $1-58$. 